\title{
Continuous wave Doppler echocardiography and coarctation of the aorta: gradients and flow patterns in the assessment of severity
}

Julene S Carvalho, Andrew N Redington, Elliot A Shinebourne, Michael L Rigby, Derek Gibson

\begin{abstract}
Indices of the severity of coarctation derived from non-invasive Doppler echocardiography were compared with measurements derived from cardiac catheterisation and angiography. In 24 Doppler studies from 17 children instantaneous peak systolic and diastolic gradients and time to half peak systolic and diastolic velocities were compared with the ratio of the coarctation diameter to the diameter of descending aorta at the level of diaphragm obtained from angiographic systolic frames of the aorta. A high peak systolic gradient ( $>40 \mathrm{~mm} \mathrm{Hg}$ ) or long time to half peak diastolic velocity ( $>100$ ms) (that is, maintenance of flow in diastole) were both highly specific $(100 \%)$ in detecting coarctation of the aorta where the angiographic ratio was $\leq \mathbf{0 . 5}$. Diastolic measurements, however, were more sensitive $(79 \%$ both for peak diastolic gradient and for time to half peak diastolic velocity) than systolic ( $57 \%$ for peak systolic gradient and $64 \%$ for time to half peak systolic velocity). Even higher sensitivity (93\%) was obtained when the peak systolic gradient was $>40 \mathrm{~mm} \mathrm{Hg}$ or the time to half peak diastolic velocity was $>100 \mathrm{~ms}$.
\end{abstract}

Examination by continuous wave Doppler echocardiography is an effective non-invasive method of assessing the severity of coarctation of the aorta, particularly when systolic and diastolic events are considered together. This approach overcomes the relatively low sensitivity of peak systolic gradient alone.

Department of Paediatric Cardiology, Brompton Hospital, London

J S Carvalho

A N Redington

E A Shinebourne

M L Rigby

Department of

Cardiology, Brompton

Hospital, London

D Gibson

Correspondence to

Dr Julene S Carvalho,

Department of Paediatric

Cardiology, Brompton

Hospital, National Heart and

Lung Institute, Fulham

Road, London SW3 6HP

Accepted for publication

30 January 1990 may be a large ductus and in older children an extensive collateral circulation may result in normal femoral pulses. Blood pressure measurements in the arms and legs and gradients measured across the coarctation area by Doppler echocardiography can give some indication of severity. Differences in pressures, however, depend not only on the severity of the coarctation but also on flow from collaterals and on cardiac output.

Instantaneous peak systolic gradients measured by Doppler techniques correlated well with the severity of coarctation. ${ }^{1-3}$ In some patients after coarctation repair, however, we found increased velocities in the descending aorta not associated with clinically significant coarctation. These high velocities may be related to turbulence around the operation site. The flow velocity pattern in the descending aorta in coarctation can be abnormal in diastole as well as in systole. ${ }^{45}$ Studies of the duration of flow in the descending aorta with measurements of acceleration time and anterograde flow time improved the correlation between catheterisation pressure gradients and Doppler derived gradients. ${ }^{6}$ However, measurements related to flow duration were not studied in detail. We therefore further investigated ways in which gradients and flow patterns in the descending aorta can be used to predict the angiographic severity of coarctation.

\section{Patients and methods}

Between January 1987 and June 1989 we studied 17 children with coarctation of the aorta who had cardiac catheterisation and continuous wave Doppler studies performed within 48 hours of each other. Doppler studies were performed with either a Doptek Spectrascan or a Hewlett Packard (Model 77020AC) 2.5 $\mathrm{MHz}$ probe. An electrocardiogram was recorded simultaneously on paper at $100 \mathrm{~mm} / \mathrm{s}$ speed. Seven patients underwent angioplastic balloon dilatation and measurements were taken before and after the procedure. Thus 24 pairs of measurements were available for analysis. We used continuous wave Doppler echocardiography from a standard suprasternal position to measure maximum velocity in the descending aorta. We measured the following variables (fig 1) and calculated gradients using the modified Bernoulli equation (gradient = $\left.4 V^{2}\right)^{7}$ : (a) instantaneous peak systolic gradient $(\mathrm{mm} \mathrm{Hg})$ corresponding to the maximal measured velocity; (b) early (peak) diastolic gradient $(\mathrm{mm} \mathbf{H g})$ arbitrarily measured at the end of the $T$ wave on the electrocardiogram; (c) systolic velocity half time (ms) - that is, time to half peak systolic velocity from the onset of 

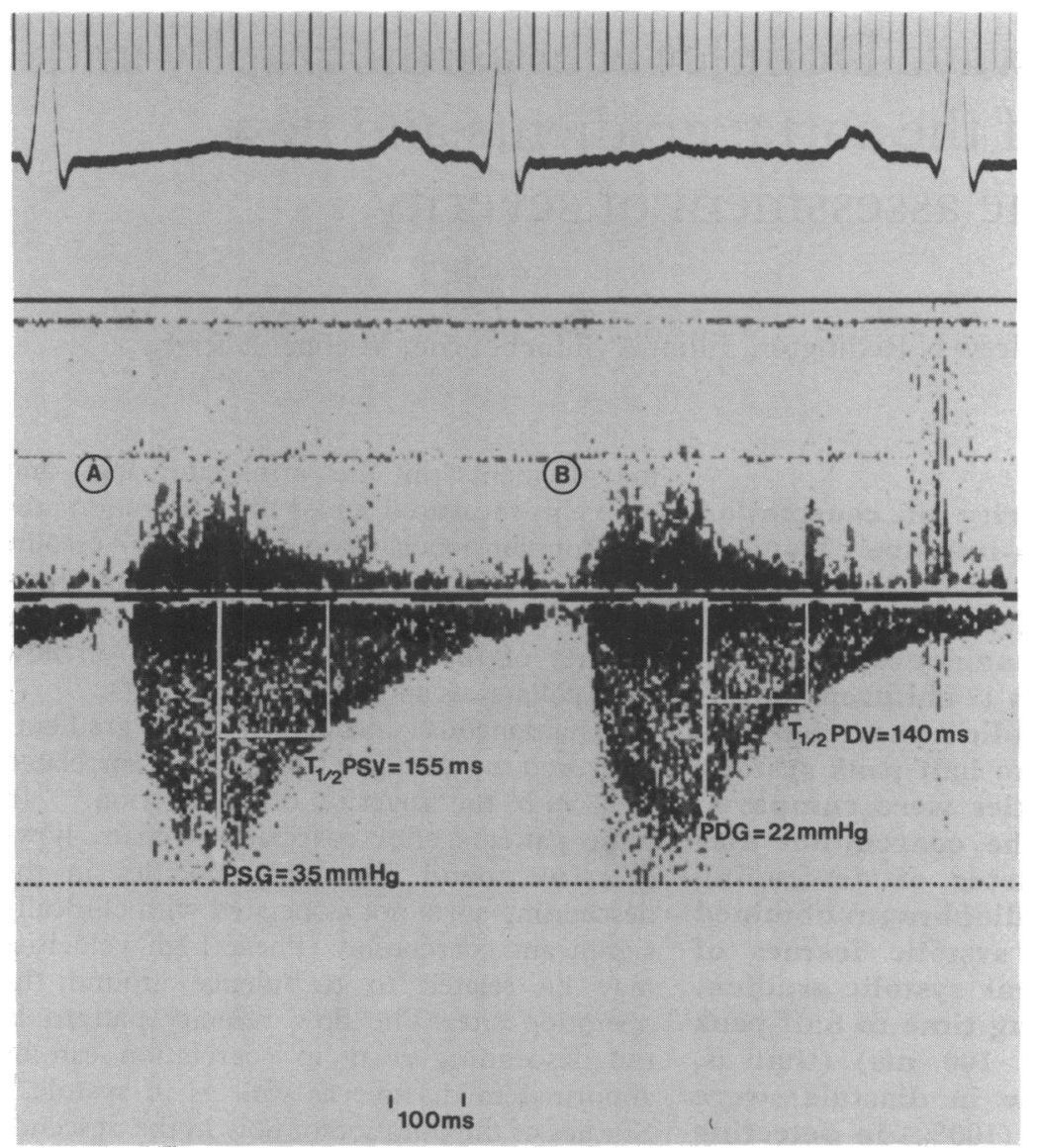

Figure 1 Continuous wave Doppler echocardiogram recorded from a suprasternal position in a patient with severe coarctation, showing systolic $(A)$ and diastolic $(B)$ measurements. PSG or PDG, peak systolic or diastolic gradient; T⿱ $\frac{1}{2} P S V$ or $T \frac{1}{2} P D V$, time to half peak systolic or diastolic velocity. ejection; and (d) diastolic velocity half time (ms)-that is, time taken for the diastolic velocity to fall to half its (peak) early value (at the end of the $T$ wave).

We studied systolic frames that showed the maximal diameter on the aortogram or left ventriculogram and which showed the coarctation site and descending aorta at the level of the diaphragm. A diagram was copied from the projected aortogram in straight lateral or left anterior oblique view in all but two patients, when an anteroposterior projection was used. To control for age, weight, and $x$ ray magnification, we measured the minimal diameter of the coarctation and expressed it as a ratio of the descending aorta at the level of the diaphragm (fig 2). Two independent observers analysed 22 of the 24 angiograms without previous knowledge of the measurements and subjectively graded the coarctation as severe, moderate, mild, or non-existent.

\section{ANALYSIS OF DATA}

The observer's subjective (but blind) angiographic assessment of severity was compared with the angiographic ratio. The data were evaluated for interobserver variablity, for the relation of subjective category to angiographic ratio, and for whether Doppler measurements and angiographic ratio correlate with decision to intervene. The angiographic ratio was used as the reference standard for the non-invasive measurements obtained with continuous wave Doppler.

Each of the Doppler measurements and the angiographically determined ratios were placed in rank order. Matrices of Spearman rank correlation coefficients for the basic data were then calculated to identify which Doppler measurements, when analysed as independent measurements, correlated with the angiographic index of severity.

Results

Table 1 shows the results of all measurements.

ANGIOGRAPHIC ASSESSMENT (TABLE 2)

All patients with an angiographic ratio $\leqslant 0.5$ के were considered to have severe or moderately $\vec{\circ}$ severe coarctation by both observers and to require relief of the coarctation (surgery or $\omega$ balloon dilatation). All angiograms with ratios $>0.65$ were graded as mild or trivial coarctation by both observers and were not regarded as requiring intervention. In five patients the ratios were between 0.5 and 0.65 , and two $\omega$ (ratios 0.58 and 0.63 ) of these patients were considered to have none/mild coarctation by both observers. In the remaining three patients (ratios $0.57,0.6$, and 0.63 ) the coarctation was regarded as mild by one and moderate by the other observer. None of these three cases was regarded by the observers as requiring (nor did they undergo) intervention.

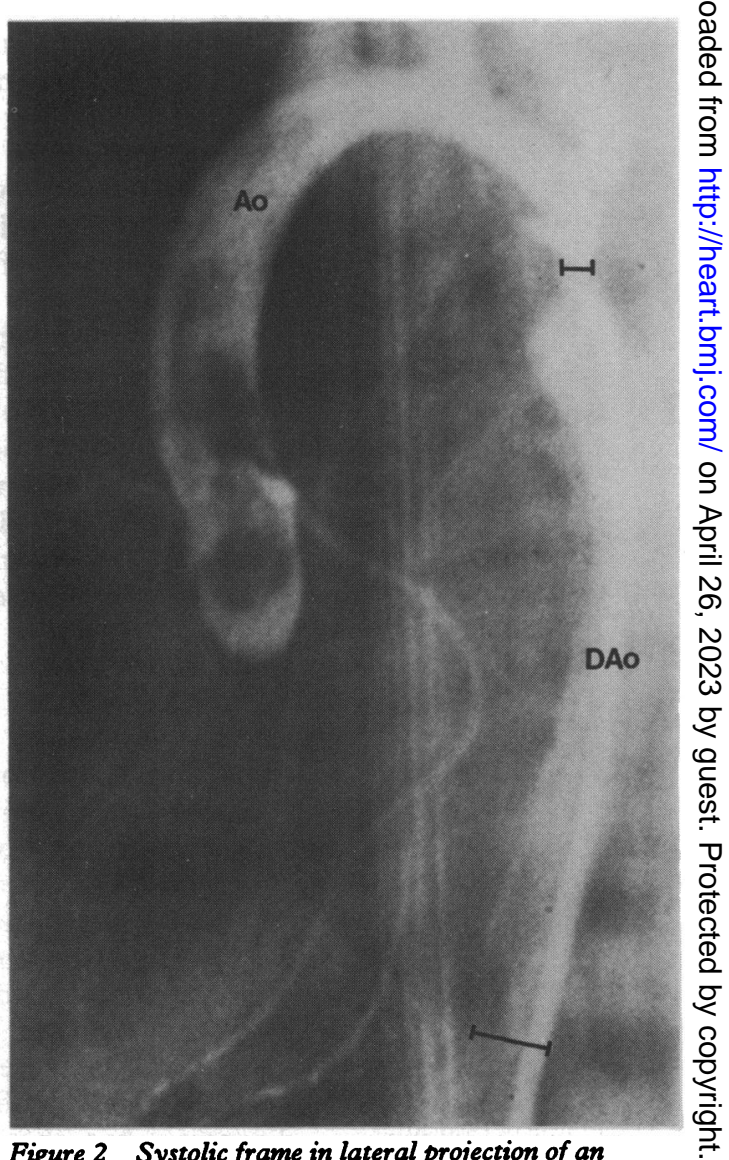

Figure 2 Systolic frame in lateral projection of an angiogram of the ascending aorta. The measurements of coarctation diameter and diameter of descending aorta at the level of diaphragm that were used to calculate the angiographic ratio are shown. 
Table 1 Measurements by Doppler echocardiography and angiography

\begin{tabular}{|c|c|c|c|c|c|c|}
\hline \multicolumn{2}{|c|}{ Patient } & \multirow[b]{2}{*}{$\begin{array}{l}\text { Ratio } \\
0.33 \\
0.72 \\
0.68 \\
0.50 \\
0.63 \\
0.63 \\
0.57 \\
0.49 \\
0.45 \\
0.13 \\
0.29 \\
0.22 \\
0.43 \\
0.30 \\
1.00 \\
0.41 \\
0.82 \\
0.27 \\
0.25 \\
0.60 \\
0.20 \\
0.57 \\
0.27 \\
0.80\end{array}$} & \multirow[b]{2}{*}{$\begin{array}{l}\begin{array}{l}P S G \\
(\mathrm{~mm} \mathrm{Hg})\end{array} \\
49 \\
29 \\
28 \\
50 \\
17 \\
33 \\
18 \\
21 \\
52 \\
63 \\
25 \\
45 \\
39 \\
43 \\
17 \\
60 \\
14 \\
12 \\
37 \\
33 \\
55 \\
32 \\
31 \\
12\end{array}$} & \multirow[b]{2}{*}{$\begin{array}{l}P D G \\
(m m H g) \\
32 \\
9 \\
6 \\
35 \\
1 \\
28 \\
5 \\
16 \\
44 \\
50 \\
23 \\
32 \\
2 \\
27 \\
0 \cdot 7 \\
48 \\
4 \\
5 \\
20 \\
6 \\
30 \\
11 \\
12 \\
0\end{array}$} & \multirow[b]{2}{*}{$\begin{array}{c}T \frac{1}{2} P S V \\
\text { (ms) } \\
210 \\
120 \\
90 \\
105 \\
60 \\
120 \\
100 \\
160 \\
260 \\
325 \\
150 \\
370 \\
110 \\
85 \\
110 \\
135 \\
110 \\
175 \\
200 \\
120 \\
245 \\
155 \\
120 \\
85\end{array}$} & \multirow[b]{2}{*}{$\begin{array}{c}T \frac{1}{2} P D V \\
(m s) \\
135 \\
30 \\
45 \\
55 \\
50 \\
80 \\
20 \\
135 \\
215 \\
335 \\
125 \\
400 \\
10 \\
35 \\
0 \\
125 \\
25 \\
240 \\
120 \\
20 \\
170 \\
80 \\
130 \\
0\end{array}$} \\
\hline $\begin{array}{r}1 \\
1 \\
2 \\
3 \\
3 \\
4 \\
5 \\
6 \\
7 \\
8 \\
9 \\
10 \\
11 \\
12 \\
12 \\
13 \\
13 \\
14 \\
15 \\
15 \\
16 \\
16 \\
17 \\
17\end{array}$ & $\begin{array}{l}\text { Before } \\
\text { Before } \\
\text { After } \\
\text { Before } \\
\text { After } \\
\text { Before } \\
\text { After } \\
\text { Before } \\
\text { After } \\
\text { Before } \\
\text { After }\end{array}$ & & & & & \\
\hline
\end{tabular}

Before and After refer to balloon dilatation.

PSG or PDG, peak systolic or diastolic gradients; $T \frac{1}{2}$, time to half peak systolic or diastolic velocity.

Table 2 Angiographic assessment of severity of coarctation

\begin{tabular}{|c|c|c|c|c|}
\hline \multicolumn{2}{|c|}{ Patient } & \multirow[b]{2}{*}{$\begin{array}{l}\text { Ratio } \\
0.33 \\
0.72 \\
0.68 \\
0.50 \\
0.63 \\
0.63 \\
0.57 \\
0.49 \\
0.45 \\
0.13 \\
0.29 \\
0.22 \\
0.43 \\
0.30 \\
1.00 \\
0.41 \\
0.82 \\
0.27 \\
0.25 \\
0.60 \\
0.20 \\
0.58 \\
0.27 \\
0.80\end{array}$} & \multirow[b]{2}{*}{$\begin{array}{l}\text { Observer } 1 \\
\text { Severe } \\
\text { Mild } \\
\text { Mild } \\
\text { Severe } \\
\text { Moderate } \\
\text { Mild } \\
\text { Moderate } \\
\text { Severe } \\
\text { Moderate } \\
\text { Severe } \\
\text { Severe } \\
\text { Severe } \\
\text { Severe } \\
\text { NA } \\
\text { NA } \\
\text { Severe } \\
\text { None } \\
\text { Severe } \\
\text { Severe } \\
\text { Moderate } \\
\text { Severe } \\
\text { None } \\
\text { Severe } \\
\text { None }\end{array}$} & \multirow[b]{2}{*}{$\begin{array}{l}\text { Observer } 2 \\
\text { Severe } \\
\text { Mild } \\
\text { Mild } \\
\text { Severe } \\
\text { Mild } \\
\text { Mild } \\
\text { Mild } \\
\text { Severe } \\
\text { Moderate } \\
\text { Severe } \\
\text { Severe } \\
\text { Severe } \\
\text { Mod severe } \\
\text { NA } \\
\text { NA } \\
\text { Severe } \\
\text { None } \\
\text { Mod severe } \\
\text { Mod severe } \\
\text { Trivial } \\
\text { Severe } \\
\text { Trivial/none } \\
\text { Severe } \\
\text { None }\end{array}$} \\
\hline $\begin{array}{r}1 \\
1 \\
2 \\
3 \\
3 \\
4 \\
5 \\
6 \\
7 \\
8 \\
9 \\
10 \\
11 \\
12 \\
12 \\
13 \\
13 \\
14 \\
15 \\
15 \\
16 \\
16 \\
17 \\
18\end{array}$ & $\begin{array}{l}\text { Before } \\
\text { After } \\
\text { Before } \\
\text { After } \\
\text { Before } \\
\text { After }\end{array}$ & & & \\
\hline
\end{tabular}

NA, not available; Mod severe, moderately severe. Before and After refer to balloon dilatation.

\section{DOPPLER ASSESSMENT}

Because none of the patients with an angiographic ratio $>0.5$ was thought by either observer to require surgery or balloon dilatation, we elected to make this value a clinically important discriminant. We therefore examined the sensitivity and specificity of Doppler measurements for detecting patients with ratios above and below this value.

High systolic gradients or long decay times were specific for significant coarctation. In this series we obtained $100 \%$ specificity and $100 \%$ predictive value for detecting coarctation with an angiographic ratio $\leqslant 0.5$ if the peak systolic gradient was $>40 \mathrm{~mm} \mathrm{Hg}$ and/or time to half peak diastolic velocity was $>100 \mathrm{~ms}$. Conversely, lower sensitivities were seen for each of the individual measurements, although diastolic variables were more sensitive and had better predictive values for a negative test than systolic measurements. This relatively low sen- sitivity of the Doppler technique was greatly improved when we considered the peak systolic gradient and peak diastolic velocity half time together-that is, whether there was either a peak systolic gradient $>\mathbf{4 0} \mathbf{m m ~} \mathbf{H g}$ or a long time to half peak diastolic velocity (>100 ms) (table 3). A plot of the angiographic ratios and time to half peak diastolic velocity shows the validity of this particular measurement (fig 5).

Matrices of the Spearman correlation coefficient showed that each of the individual Doppler measurements correlated with the angiographic ratio. Table 3 gives details of each correlation coefficient and significance level. All values were significant ( $p<0.003$ ), but the negative correlations between times to half peak systolic and to half peak diastolic velocities and the angiographic ratios were stronger than the correlation between peak systolic and diastolic gradients and the angiographic ratios. So it is likely that the longer the time to half maximal velocities (persistence of flow in diastole) the smaller the ratios (the more severe the coarctation).

\section{Discussion}

In the presence of coarctation of the aorta various factors can influence the flow pattern in the descending aorta. ${ }^{8}$ The cross sectional area and length of the narrowed segment and the presence of a collateral circulation or a large ductus arteriosus are contributing factors, as is the cardiac output. The resultant pattern of flow to the descending aorta is, therefore, related to a complex interaction of all these factors. The limitations of using the Doppler technique to diagnose coarctation of the aorta in neonates have been recently emphasised. ${ }^{9}$

The pattern of flow velocity in the descending aorta in the presence of coarctation is qualitatively characteristic. High systolic velocities reflect the presence of a pressure drop between the proximal and distal aorta during ejection. High velocities also persist during diastole. In mild cases these have returned to baseline by mid diastole; but when coarctation is more severe, high velocities continue throughout diastole. It thus seems to us that not only might the patterns of diastolic flow provide a means of measuring the severity of coarctation but also that such patterns may reflect an aspect of the disturbance to normal physiology quite distinct from a simple reduction in peak perfusion pressure. This diastolic pressure drop can be considered as equivalent to a potential generated by a capacitance decaying across a resistance; so it can be modelled as an exponential. We therefore chose to measure its severity as a simple velocity half time. Obviously, conditions are more complex than this, particularly where there is a large collateral flow which could cause pressure to equilibrate rapidly regardless of the severity of the coarctation itself. Even so, we believed that measuring the decay time would give information related to the severity of obstruction in the presence of collaterals, and that the clinical value of such measurement might usefully be explored. 


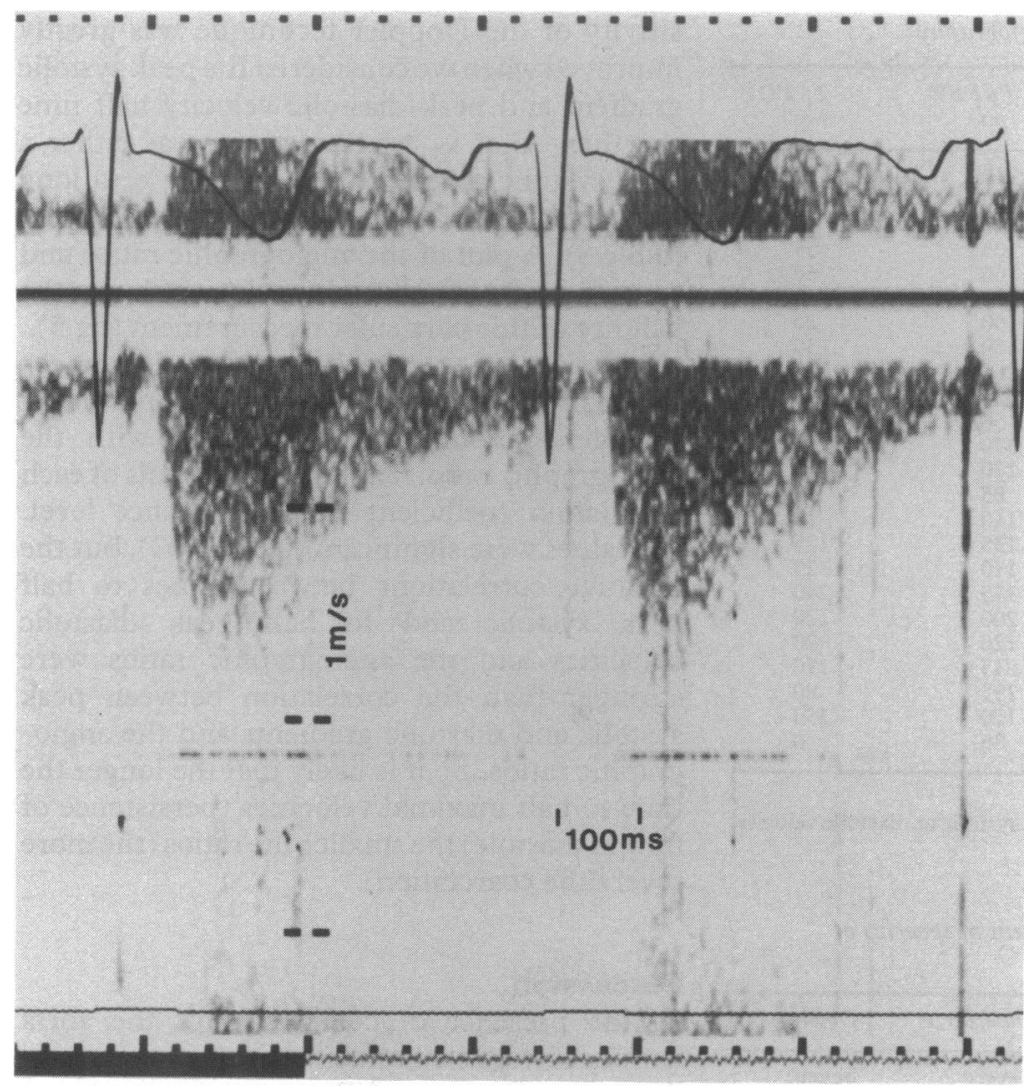

Figure 3 Continuous wave Doppler echocardiogram recorded in a patient with severe coarctation of the aorta (ratio $=0 \cdot 27$ ). Note slight increase in maximal systolic velocity (gradient $=12 \mathrm{~mm} \mathrm{Hg}$ ) but long diastolic velocity half time $(240 \mathrm{~ms})$.
Our results showed that the specificity of Doppler measurements in identifying severe coarctation of the aorta is high if there is an important gradient or flow that is maintained in diastole. In six patients severe coarctation would have been missed if only high peak systolic gradients had been considered. This low sensitivity could be greatly improved by analysing the peak diastolic velocity half time. This approach makes it possible to identify those patients with severe coarctation in whom lower velocities (and consequently lower gradients) are present. In this series only one patient (case 11) with a severe lesion would not have been definitely identified by the combination of the two measurements. However, even in this case the peak systolic gradient was nearly $40 \mathrm{~mm} \mathrm{Hg}$.

This analysis shows that the validity of the Doppler technique for assessment of severity of coarctation of the aorta can be significantly improved by the additional assessment of flow patterns. The factors that influence the presence of high velocity across the narrowed segment or persistence of flow in diastole in the descending aorta are certainly complex, but the presence of only one of these measurements seems to be enough to confirm that the coarctation is appreciable and warrants intervention. A very small number of patients, however, may still require cardiac catheterisation if measurements are borderline and there is uncertainty about the severity of coarctation on clinical grounds.

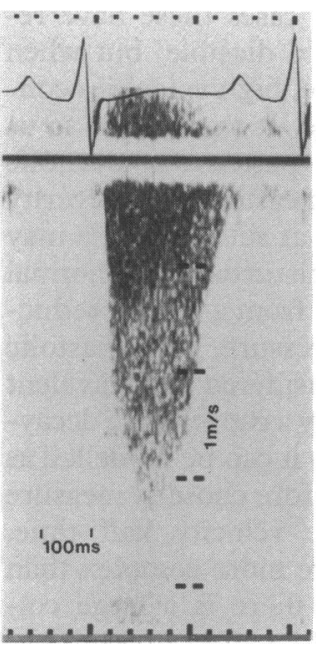

Figure 4 Continuous wave Doppler echocardiogram recorded in a patient with severe coarctation (ratio $=$ $0 \cdot 30$ ), high peak systolic gradient $(43 \mathrm{~mm} \mathrm{Hg})$, and short decay time ( $35 \mathrm{~ms})$.
Table 3 Performance of Doppler echocardiographic measurements in detecting coarctation when the angiographic ratio was $\leqslant 0.5$

\begin{tabular}{|c|c|c|c|c|c|}
\hline & $\begin{array}{l}\text { Sensitivity } \\
(\%)\end{array}$ & $\begin{array}{l}\text { Specificity } \\
(\%)\end{array}$ & $\begin{array}{l}\text { Predictive value } \\
\text { of positive test } \\
(\%)\end{array}$ & $\begin{array}{l}\text { Predictive value } \\
\text { of negative test } \\
(\%)\end{array}$ & $\begin{array}{l}\text { Spearman rank } \\
\text { correlation }(p)\end{array}$ \\
\hline PSG $>40 \mathrm{~mm} \mathrm{Hg}$ & 57 & 100 & 100 & 63 & \multirow{5}{*}{$\begin{array}{l}-0.57 \\
(0.003) \\
-0.67 \\
(<0.001) \\
-0.61 \\
(0.001) \\
-0.76 \\
(<0.001)\end{array}$} \\
\hline $\mathrm{T} \frac{1}{2} \mathrm{PSV}>140 \mathrm{~ms}$ & 64 & 90 & 90 & 64 & \\
\hline PDG $>15 \mathrm{~mm} \mathrm{Hg}$ & 79 & 90 & 92 & 75 & \\
\hline $\mathrm{T} \frac{1}{2} \mathrm{PDV}>100 \mathrm{~ms}$ & 79 & 100 & 100 & 77 & \\
\hline $\begin{array}{r}\text { PSG }>40 \mathrm{~mm} \mathrm{Hg} \text { or } \\
\mathrm{T} \frac{1}{2} \mathrm{PDV}>100 \mathrm{~ms}\end{array}$ & 93 & 100 & 100 & 91 & \\
\hline
\end{tabular}

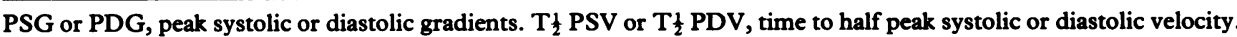

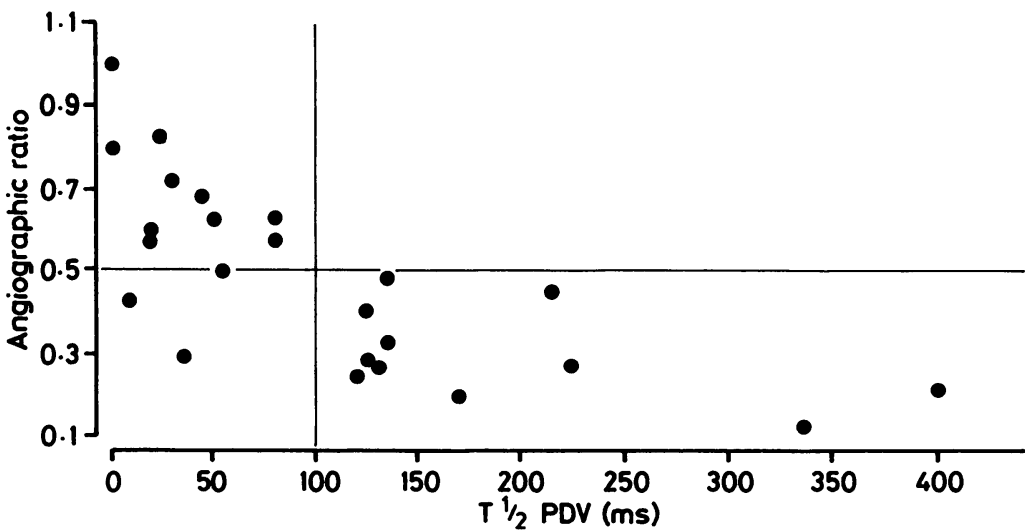

Figure 5 Angiographic ratio plotted against time to half peak diastolic velocity to show the validity of this measurement. There were no false positive (right upper corner) and three false negative results (left lower corner). True positive measurements are shown in the right lower corner and true negative on the left upper corner. 
1 Wyse RKH, Robinson PJ, Deanfield JE, Tunstall Pedoe DS, Macartney FJ. Use of continuous wave Doppler ultrasound velocimetry to assess the severity of coarctation of the aorta by measurement of aortic flow velocities. $\mathrm{Br}$ of the aorta by measure
Heart $J$ 1984;52:278-83.

2 Robinson PJ, Wyse RKH, Deanfield JE, Franklin R, Macartney FJ. Continuous wave Doppler velocimetry as an adjunct to cross sectional echocardiography in the diagnosis of critical left heart obstruction in neonates. Br Heart J 1984;52:552-6.

3 Marx GR, Allen HD. Accuracy and pitfalls of Doppler evaluation of the pressure gradient in aortic coarctation. $J$ Am Coll Cardiol 1986;7:1379-85.

4 Hatle L, Angelsen B. Doppler ultrasound in cardiology physical principles and clinical applications. Philadelphia: Lea and Febiger, 1985:217-21.

5 Houston $\mathrm{AB}_{1}$ Simpson IA, Pollock JCS, Jamieson MPG,
Doig WB, Coleman EN. Doppler ultrasound in the assessment of severity of coarctation of the aorta and interruption of the aortic arch. Br Heart J 1987;57:38-43. 6 Syamasundar Rao P, Carey P. Doppler ultrasound in the prediction of pressure gradients across aortic coarctation. prediction of pressure gradients

7 Hatle L, Angelsen B. Doppler ultrasound in cardiology: physical principles and clinical applications. Philadelphia: Lea and Febiger, 1985:24.

8 Teirstein PS, Yock PG, Popp RL. The accuracy of Doppler ultrasound measurement of pressure gradient across irregular, dual and tunnellike obstructions to blood flow. Circulation 1985;72:577-84.

9 Wilson N, Sutherland GR, Gibbs JL, Dickinson DF, Keeton BR. Limitations of Doppler ultrasound in the diagnosis of neonatal coarctation of the aorta. Int J Cardiol 1989;23:87-9. 